\title{
PENGARUH INTERFERENSI BLUETOOTH 5.0 TERHADAP KINERJA JARINGAN 802.11b
}

\author{
Fany Fahmi Faizar ${ }^{1}$ \\ ${ }^{1}$ Universitas Muhammadiyah Malang \\ e-mail: FanyFahmiFaizar@gmail.com ${ }^{1}$
}

\begin{abstract}
Abstrak
IEEE $802.11 \mathrm{~b}$ adalah standar teknologi komunikasi antar perangkat elektronik yang memanfaatkan gelombang radio frekuensi 2,4 Ghz sebagai media transmisi. Banyak jenis jaringan nirkabel yang juga memanfaatkan radio frekuensi 2,4 Ghz sebagai media transmisi, salah satunya adalah jaringan bluetooth. Jaringan bluetooth merupakan jaringan nirkabel dengan untuk komunikasi tanpa batas pada jarak yang pendek dan membutuhkan konsumsi daya yang rendah. Pertemuan 2 jaringan nirkabel yang memiliki spektrum pita frekuensi yang sama memungkinkan terjadinya penurunan performa pada jaringan nirkabel tersebut Pada penelitian ini menguji pengaruh dari jumlah interferensi bluetooth 5.0 terhadap kinerja jaringan Wi-Fi dengan menggunakan parameter QoS Video streaming sebagai tolak ukur untuk melakukan analisis data hasil pengujian. Dari hasil analisis, dapat diketahui semakin banyak jumlah interferensi bluetooth maka nilai delay maupun nilai packet loss semakin meningkat dan nilai throughput semakin menurun. Hal tersebut menunjukkan jumlah interferensi bluetooth yang bertambah menyebabkan kinerja jaringan Wi-Fi menurun.
\end{abstract}

Kata kunci: 802.11b, Video Streaming, Interferensi Jaringan, Bluetooth 5.0

\section{Abstract}

IEEE $802.11 \mathrm{~b}$ is a communication technology standard between electronic devices that utilizes $2.4 \mathrm{GHz}$ radio frequency waves as a transmission medium. Many types of wireless networks also utilize $2.4 \mathrm{GHz}$ radio frequency as a transmission medium, one of them is a bluetooth network. Bluetooth network is a wireless network with unlimited communication for short distances and requires low power consumption. when 2 wireless networks that have the same frequency band spectrum meet, allowing a decrease in performance on the wireless network. In this study the authors tested the effect of the amount of Bluetooth 5.0 interference on Wi-Fi network performance by using QoS parameters Video streaming as a benchmark for analysis test result data. From the analysis result, when the amount of bluetooth interference increased, the value of delay and packet loss is increased and the value of throughput is decreased. This shows that the increasing amount of bluetooth interference causes Wi-Fi network performance decreased.

Keywords: 802.11b, Video Streaming, Network Interference, Bluetooth 5.0

\section{Pendahuluan}

\subsection{Latar Belakang}

Teknologi WLAN (Wireless Local Area Network) IEEE 802.11b biasa disebut juga dengan Wi-Fi merupakan jaringan nirkabel terkemuka alternatif yang mengkoneksikan satu perangkat dengan lainnya ke internet melalui gelombang radio sebagai media atau perantara dengan kecepatan pengiriman data hingga $11 \mathrm{Mbps}$ dan cakupan area hingga 300 meter[1]. Selain jaringan Wi-Fi, jaringan bluetooth juga menjadi salah satu jaringan nirkabel yang selalu dimiliki oleh setiap perangkat dikarenakan konsumsi dayanya yang rendah. Jaringan bluetooth menjadi pilihan terbaik saat ini untuk menghubungkan antar perangkat secara point to point pada area lokal dengan cakupan area kurang dari 5 meter[2]. Jaringan Wi-Fi maupun bluetooth menggunakan spektrum pita frekuensi pada tingkat yang sama di $2,4 \mathrm{GHz}$. Pertemuan dua jaringan tersebut mengakibatkan terjadinya interferensi antar jaringan dan berdampak buruk pada kualitas jaringan itu sendiri. Interferensi dapat terjadi dikarenakan media trasmisi pada jaringan nirkabel bersifat terbuka dan dapat diakses oleh semua pemancar dan perangkat nirkabel apapun pada pita frekuensi yang sama dapat menyebabkan penurunan kualitas sinyal dan teknologi nirkabel 802.11 seperti jaringan Wi-Fi dan bluetooth dapat terganggu[3].

Penelitian yang dilakukan Hasad, melakukan pengembangan sistem piconet pervasive dengan melakukan analisis pengaruh interferensi Wi-Fi pada video streaming melalui jaringan 
bluetooth dengan memanfaatkan media selular dan komputer. Pengujian dilakukan pada lingkungan yang memiliki jaringan Wi-Fi maupun tidak memiliki jaringan Wi-Fi dengan jarak 4 meter antara server dan client[4].

Penelitian yang dilakukan Chaube, membahas tentang interferensi antara jaringan Wi-Fi dan bluetooth pada satu perangkat yang sama. Penelitian ini menggunakan perangkat selular sebagai alat uji dengan skenario satu perangkat mengakses dua jaringan berbeda yaitu jaringan Wi-Fi dan bluetooth dalam waktu yang bersamaan dengan coverage kedua jaringan tersebut kurang dari dua meter yang dilakukan di area indoor dan parameter yang diuji mengacu pada packet loss dan throughput[5].

Penelitian lain oleh Purwaningsih, melakukan pengujian tentang Quality of service terhadap interferensi bluetooth pada Wi-Fi 802.11b. pengujian dilakukan pada area indoor dan outdoor. Jaringan yang digunakan adalah jaringan Wi-Fi dan bluetooth dengan skenario pengujian menggunakan satu laptop sebagai server dan satu laptop lain sebagai client yang terhubung ke jaringan Wi-Fi dimana jaringan tersebut satu frekuensi dengan bluetooth 3.0 dan 4.0. Pengujian dilakukan pada jarak 1, 2, 3 dan 4 meter menggunakan software Wireshark dengan parameter delay, throughput dan packet loss yang dibebani oleh video streaming[6].

Berdasarkan beberapa penelitian diatas, maka dalam penelitian ini berfokus pengujian jumlah interferensi yang disebabkan oleh jaringan bluetooth 5.0 terhadap kinerja jaringan Wi-Fi. Perangkat yang digunakan pada penelitian ini adalah 1 perangkat komputer sebagai server, 1 perangkat komputer sebagai client, 4 perangkat bluetooth versi 5.0, 1 perangkat router. pengujian akan dilakukan dengan variasi jarak 1,2,3 dan 4 meter pada area indoor dan outdoor dengan 3 skenario pengujian, yaitu penambahan interferensi 0 perangkat bluetoooth, 2 perangkat bluetooth, dan 4 perangkat bluetooth secara bergantian. Parameter pengujian menggunakan delay, throghput, dan packet loss yang dibebani oleh video streaming dengan resolusi 1080p.

\subsection{Standar Protokol IEEE 802.11}

\begin{tabular}{|c|c|c|c|c|c|c|c|c|c|c|c|c|}
\hline \multirow{2}{*}{$\begin{array}{l}\text { WLAN } \\
\text { Standurd }\end{array}$} & \multirow[t]{2}{*}{ PHY Term } & \multicolumn{2}{|c|}{$\begin{array}{l}\text { Frekuensi } \\
\text { (Ghz) }\end{array}$} & \multicolumn{4}{|c|}{$\begin{array}{l}\text { Mekanisme Penyebaran } \\
\text { Spektrum Radio }\end{array}$} & \multirow{2}{*}{$\begin{array}{l}\text { Lebar Pita } \\
\text { Saluran } \\
(\mathrm{MHz})\end{array}$} & \multirow{2}{*}{$\begin{array}{c}\text { RF } \\
\text { Modulation } \\
\text { dan Coding } \\
\text { Scheme } \\
\end{array}$} & \multirow{2}{*}{$\begin{array}{l}\text { Sistem } \\
\text { Antena }\end{array}$} & \multirow{2}{*}{$\begin{array}{c}\text { Spatial } \\
\text { Data } \\
\text { Stream } \\
\text { (Max.) }\end{array}$} & \multirow{2}{*}{$\begin{array}{l}\text { Datarate } \\
\text { (Mbps) } \\
\text { (Max.) }\end{array}$} \\
\hline & & 2.4 & 5 & FHSS & DSSS & IR & ODFM & & & & & \\
\hline $802.11-1997$ & FHSS/DSSS & $\mathrm{v}$ & & $\mathrm{v}$ & $\mathrm{v}$ & $\mathrm{v}$ & & 20 & FSK & & & \\
\hline PSK & SISO & 1 & 2 & & & & & & & & & \\
\hline $802.11 \mathrm{a}-1999$ & ODFM & & $\mathrm{v}$ & & & & $\mathrm{v}$ & 20 & 64 QAM & SISO & 1 & 54 \\
\hline $802.11 \mathrm{~b}-1999$ & HR/DSSS & $\mathrm{v}$ & & & $\mathrm{v}$ & & & 20 & $\mathrm{CCK}$ & SISO & 1 & 11 \\
\hline $802.11 \mathrm{~g}-2003$ & ERP PHY & $\mathrm{v}$ & & & $\mathrm{v}$ & & $\mathrm{v}$ & 20 & CCK & siso & 1 & 54 \\
\hline 802.11n-2009 & HT PHY & $\mathrm{v}$ & $\mathrm{v}$ & & $\mathrm{v}$ & & $\mathrm{v}$ & 20/40 & 64 QAM & MIMO & 4 & 600 \\
\hline 802.11 ac-2013 & VHT PHY & & $\mathrm{v}$ & & $\mathrm{v}$ & & v & $20 / 40 / 80 / 160$ & $256 \mathrm{QAM}$ & MU-MIMO & 8 & 6933.3 \\
\hline
\end{tabular}

Gambar 1 Spesifikasi 802.11[7]

Standarisasi jaringan Wireless LAN adalah IEEE 802.11, IEEE (institute of eletrical and electronic enginering) merupakan institusi yang melakukan diskusi, riset dan pengembangan terhadap perangkat jaringan yang kemudian menjadi standarisasi untuk digunakan sebagai perangkat jaringan [7]

\subsection{Topologi Jaringan}

Topologi dari suatu jaringan adalah kunci untuk menentukan kinerja maksimum dari suatu jaringan tersebut. Menurut Zymon Machajewski topologi adalah seperangkat komputer yang saling terhubung dengan komputer lainya yang secara bersamaan dengan tujuan utama untuk saling berbagi dan menggunakan sumber daya Bersama-sama[8]. Dalam jaringan Wi-Fi memiliki 2 jenis topologi utama, yaitu infrastruktur dan adhoc. Mode adhoc merupakan sebuah metode yang memungkinkan pertukaran data antar perangkat tanpa memerlukan router sebagai perantara kedua perangkat tersebut. Pada mode infrastruktur membutuhkan router agar dapat terhubung dalam sebuah WLAN, Router dan perangkat client yang lain terlebuh dahulu melakukan konfigurasi untuk mendapatkan konfigurasi SSID yang sama.

\subsection{Channel Frekuensi}

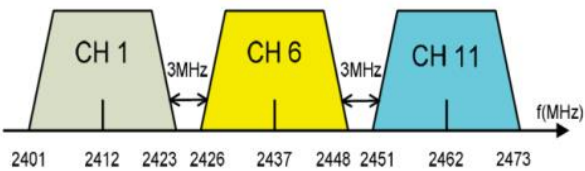

Gambar 2 Non-overlaping Channel Wi-Fi[9] 
Pengaturan saluran Channel router dilakukan dengan tujuan mencegah terjadinya penumpukan Channel dalam ruang lingkup yang sama. Memilih satu atau lebih saluran Channel adalah hal penting dari pengaturan jaringan Wi-Fi agar tidak terjadi penurunan kualitas jaringan. Pada pita frekuensi 2,4 Ghz, saluran Channel yang umum digunakan agar mendapat kemungkinan kecil terjadi overlaping adalah 1, 6, dan 11[9].

\subsection{Jaringan Bluetooth}

Jaringan bluetooth adalah jaringan yang ditujukan untuk jaringan jarak pendek dan membutukan konsumsi daya yang rendah. Awal mula munculnya bluetooth pada tahun 1994 dikembangkan oleh ericsson, yang selanjutnya diatur sebagai teknologi terbuka oleh Bluetooth Special Interest Group. Awal mula pengunaan bluetooth hanya digunakan sebagai teknologi pengganti kabel yang umumnya digunakan pada perangkat nirkabel. Penggunaan teknologi bluetooth saat ini dapat ditemukan pada perangkat yang umum digunakan seperti perangkat komputer, laptop, keyboard, mouse, joystick, printer dan lain sebagainya. Perangkat tersebut memiliki teknologi bluetooth untuk komunikasi tanpa batas jarak pendek dengan konsumsi daya rendah yang menggantikan komunikasi melalui kabel serial dan paralel. Menurut Prathiba teknologi bluetooth menjadi pilihan terbaik untuk jaringan adhoc masa depan bagi piranti cerdas karena potensi yang dimiliki yaitu konsumsi daya yang rendah dan biaya perangkat yang murah[10].

\subsection{Pengukuran Bluetooth}

Pada dasarnya ada tiga aspek penting dalam melakukan pengukuran bluetooth, yaitu pengukuran radio frekuensi, protokol dan profil. Pengukuran radio frequency dilakukan untuk memberikan kompatibilitas perangkat radio yang digunakan di dalam sistem dan menentukan kualitas sistem. Untuk pengukuran protokol, dapat menggunakan sniffer protocol yang dapat memantau dan menampilkan pergerakan data antar perangkat bluetooth. Sementara dalam pengukuran profil itu dilakukan untuk memastikan interoperability antar perangkat dari derbagai jenis vendor[11].

\subsection{Bluetooth Versi 5.0}

Dalam beberapa tahun terakhir standar teknologi bluetooth terus dikembangkan dan di perluas untuk memenuhi kebutuhan pasar Internet of Things dengan memperkenalkan teknologi bluetooth generasi terbaru yaitu bluetooth 5.0. pada peluncuran teknologi bluetooth 5.0 oleh SIG (Special Interest Group) dekatkan bahwa teknologi ini memiliki keunggulan 2 kali lebih cepat, cakupan area 4 kali lebih luas, dan kapasitas broadcast 8 kali lebih besar dari teknologi bluetooth 4.0[10].

\subsection{Dampak Interferensi Bluetooth}

Pemakaian radio frekuensi pada modul bluetooth juga berdampak pada interferensi teknologi jaringan lain yang memanfaatkan frekuensi radio sebagai media transmisi. Persoalan yang sering terjadi adalah melonjaknya tingkat penggunaan 802.11 Wireless $L A N$ yang menyebabkan interferensi antar wireless $L A N$ sering terjadi. Interferensi bisa terjadi karena terdapat lebih dari satu jaringan nikkabel dalam area yang berdekatan dan menggunakan tingkat frekuensi radio yang sama, salah satu persoalan yang sering ditemui adalah interferensi antara jaringan Wi-Fi dan Bluetooth[10]. Perbedaan yang sangat mendasar dari perangkat Wi-Fi dan bluetooth adalah digunakannya teknik frequency hopping pada bluetooth menggunakan seluruh pita frekuensi. Sedangkan teknologi Wi-Fi menggunakan teknik direct sequence dan hanya menggunakan $1 / 3$ pita frekuensi 2,4 Ghz.

\subsection{Quality of Service}

Komunikasi jaringan membentuk Backbone untuk mencapai struktur jaringan yang baik. Pada jaringan yang baik, mampu mengirim data berkapasitas besar termasuk video berkualitas tinggi dan data yang sangat sensitif terhadap delay seperti real-time VOIP (Voice over internet protocol). Perangkat lunak seperti bandwith-intensive dapat memperluas kapasitas jaringan, tetapi juga meningkatkan proses aktifitas yang terjadi pada jaringan itu sendiri. Jaringan harus menyediakan layanan yang aman, dapat diprediksi dan diukur. Untuk memenuhi kebutuhan QoS (Quality of Service) perlu adanya pengolahan delay, throughput, dan parameter packet loss pada jaringan. Dengan demikian QoS merupakan serangkaian teknik pengolahan network resources[12]. 


\subsection{Alur Penelitian}

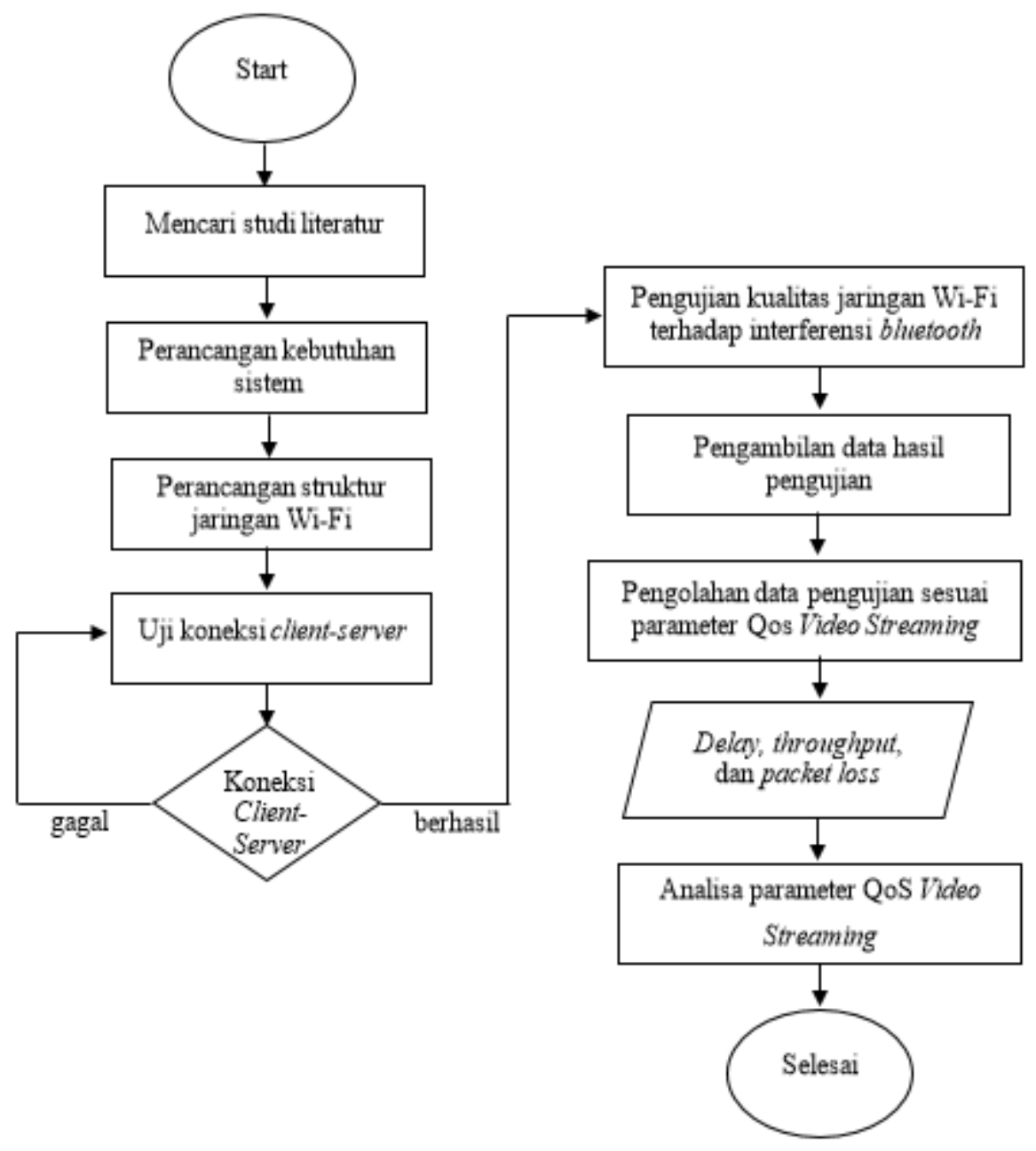

Gambar 3 Flowchart Alur Penelitian

Pada gambar 3 menjelaskan tentang alur rancangan penelitian. Alur Penelitian dimulai dengan studi literatur dari beberapa sumber terkait dan jurnal, dengan bahasan mengenai jaringan $\mathrm{Wi}-\mathrm{Fi}$, jaringan bluetooth, interferensi jarigan nirkabel, video streaming, dan quality of service beserta parameter yang digunakan. selanjutnya perancangan kebutuhan sistem dilakukan untuk mengetahui kebutuhan dari seluruh struktur sistem yang digunakan dalam penelitian ini. Setelah segala kebutuhan telah tercapai, perancangan struktur jaringan dilakukan dengan atribut yang telah ditentukan pada analisa kebutuhan dan mengacu pada literatur yang telah didapat. Setelah struktur jaringan terbentuk, selanjutnya melakukan cek koneksi antar perangkat client-server agar dapat dilakukan proses pengujian berdasarkan skenario yang sudah ditentukan. Lalu masuk pada proses pengujian kualitas jaringan Wi-Fi terhadap interferensi bluetooth dengan melakukan proses video streaming untuk mendapatkan hasil monitoring lalu lintas data yang selanjutnya data tersebut akan dilakukan penghitungan berdasarkan rumus parameter QoS video streaming berupa data delay, throughput, dan packet loss. proses akhir adalah analisa parameter QoS video streaming yang sudah didapat untuk menentukan pengaruh yang disebabkan oleh interferensi bluetooth 5.0 terhadap jaringan Wi-Fi. 


\subsection{Kebutuhan Sistem}

Tabel 1 kebutuhan hardware dan software

\begin{tabular}{|l|l|l|}
\hline No & Hardware & Software \\
\hline 1 & PC Client & Wireshark \\
\hline 2 & PC Server & Inssider \\
\hline 3 & Router RB941-2nD & Winbox \\
\hline 4 & Bluetooth 5.0 & VLC Media Player \\
\hline
\end{tabular}

\subsection{Perancangan jaringan Wi-Fi}

\subsubsection{Topologi Pengujian Dengan Interferensi 0 Perangkat Bluetooth}

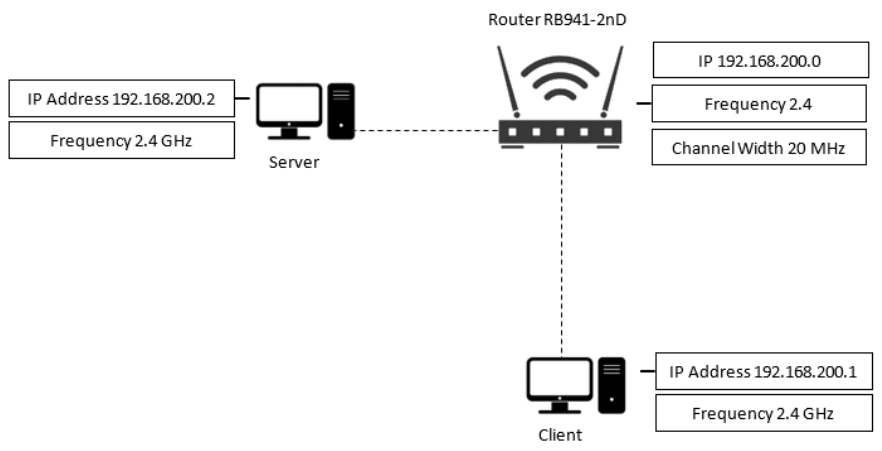

Gambar 4 Skenario pengujian tanpa interferensi bluetooth

Pada gambar Gambar 4 menunjukkan topologi pengujian video streaming menggunakan jaringan Wi-Fi pada frekuensi $2.4 \mathrm{GHz}$ tanpa dipengaruhi oleh interferensi disekitar jaringan tersebut. Proses video streaming dilakukan oleh client dan server melalui jaringan Wi-Fi yang dipancarkan oleh router RB941-2nD. Perangkat server melakukan video streaming pada jaringan lokal 192.168.200.0/24 dan perangkat client melakukan akses terhadap video streaming pada jaringan yang sama.

\subsubsection{Topologi Pengujian Dengan Interferensi 2 Perangkat Bluetooth}

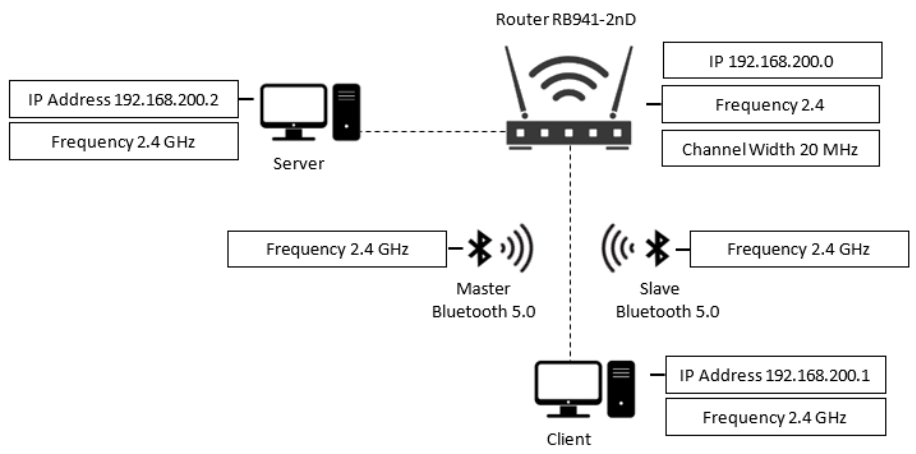

Gambar 5 Pengujian interferensi oleh 1 Master dan 1 Slave Bluetooth 5.0

Pada Gambar 5 menunjukkan topologi pengujian video streaming menggunakan jaringan Wi-Fi pada frekuensi $2.4 \mathrm{GHz}$ dan dipengaruhi oleh interferensi jaringan lain dengan frekuensi yang sama di $2.4 \mathrm{GHz}$ yaitu jaringan bluetooth 5.0 dengan 1 perangkat bluetooth sebagai slave dan 1 perangkat bluetooth sebagai master. Proses video streaming dilakukan oleh client dan server melalui jaringan $\mathrm{Wi}-\mathrm{Fi}$ yang dipancarkan oleh router RB941-2nD. Perangkat server melakukan video streaming pada jaringan lokal 192.168.200.0/24 dan perangkat client melakukan akses terhadap video streaming pada jaringan yang sama. ketika proses video streaming berlangsung, di waktu yang sama perangkat bluetooth melakukan proses pengiriman data antar slave dan master.

REPOSITOR, Vol. 2, No. 10, Oktober 2020, Pp. 1390-1399 


\subsubsection{Topologi Pengujian Dengan Interferensi 4 Perangkat Bluetooth}

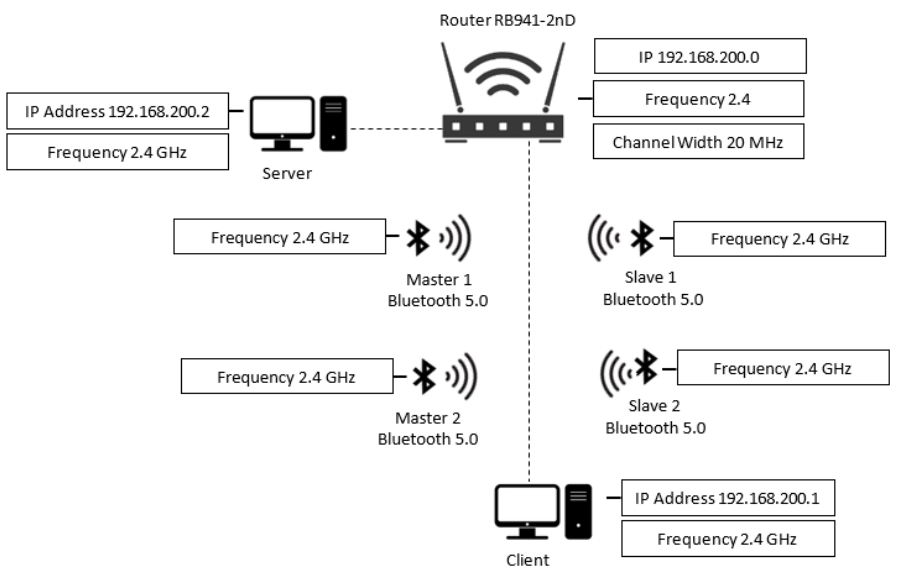

Gambar 6 Pengujian interferensi oleh 2 Master dan 2 Slave Bluetooth 5.0

Pada Gambar 6 menunjukkan topologi pengujian video streaming menggunakan jaringan Wi-Fi pada frekuensi $2.4 \mathrm{GHz}$ dan dipengaruhi oleh interferensi jaringan lain dengan frekuensi yang sama di $2.4 \mathrm{GHz}$ yaitu jaringan bluetooth 5.0 dengan 2 perangkat bluetooth sebagai slave dan 2 perangkat bluetooth sebagai master. Proses video streaming dilakukan oleh client dan server melalui jaringan Wi-Fi yang dipancarkan oleh router RB941-2nD. Perangkat server melakukan video streaming pada jaringan lokal 192.168.200.0/24 dan perangkat client melakukan akses terhadap video streaming pada jaringan yang sama. ketika proses video streaming berlangsung, di waktu yang sama perangkat bluetooth melakukan proses pengiriman data antar slave dan master.

\subsubsection{Pengujian Area Indoor}

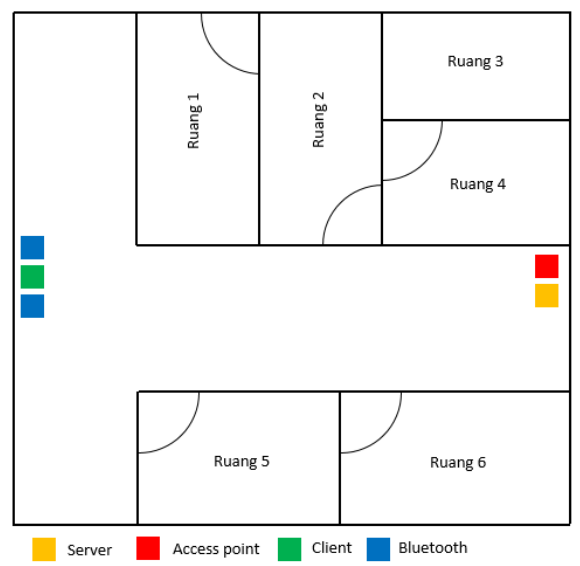

Gambar 7 Denah lokasi pengujian indoor

Pada area indoor pengujian dilakukan di ruangan tertutup tanpa dipengaruhi jaringan WiFi lain di sekitar area pengujian. Pada pengujian dilakukan pemberian jarak antara router dengan perangkat server kurang dari 1 meter dan jarak router dengan perangkat client dibagi menjadi 4 tahap yaitu dengan jarak 1,2,3 dan 4 meter. Sedangkan perangkat bluetooth sebagai interferensi diletakkan di sekitar perangkat client dengan jarak kurang dari 1 meter.

\subsubsection{Pengujian Area Outdoor}

Pada area outdoor pengujian dilakukan di ruangan terbuka dengan kondisi cuaca stabil dan tidak terdapat jaringan Wi-Fi lain disekitar area pengujian. Pada pengujian dilakukan pemberian jarak antara router dengan perangkat server kurang dari 1 meter dan jarak router dengan perangkat client dibagi menjadi 4 tahap yaitu dengan jarak 1,2,3 dan 4 meter. Sedangkan perangkat bluetooth sebagai interferensi diletakkan di sekitar perangkat client dengan jarak kurang dari 1 meter.

\subsection{Proses Pengambilan Data}


Pada penelitian ini dilakukan pengambilan data melalui wireshark dengan melakukan monitoring lalu lintas data yang terjadi pada jaringan 192.168.200.0/24. Data yang di ambil pada wireshark berupa rangkaian semua paket yang melintas pada jaringan tersebut dan selanjutnya akan diolah menjadi data parameter QoS berupa delay, throughput dan packet loss. Pengambilan data yang dilakukan pada penelitian ini memiliki beberapa faktor yang dapat mempengaruhi proses pengambilan data, yaitu :

1. Pengambilan data dilakukan pada area indoor dan outdoor tanpa dipengaruhi oleh jaringan Wi-Fi lain disekitar area pengujian.

2. Pengambilan data dilakukan dengan memberi variasi jarak antara perangkat client dan router, yaitu pada jarak 1,2,3 dan 4 meter.

3. Pengambilan data dilakukan dengan memberi variasi kondisi interferensi oleh bluetooth 5.0 , yaitu dengan jumlah perangkat bluetooth 0,2 , dan 4 perangkat.

\subsection{Parameter QoS Video Streaming}

\subsubsection{Delay(latency)}

\begin{tabular}{|c|c|c|}
\hline $\begin{array}{c}\text { Kategori } \\
\text { Latency }\end{array}$ & Latency & Indeks \\
\hline Poor & $>450 \mathrm{~s}$ & 1 \\
\hline Medium & $300-450 \mathrm{~s}$ & 2 \\
\hline Good & $150-300 \mathrm{~s}$ & 3 \\
\hline Perfect & $<150 \mathrm{~s}$ & 4 \\
\hline
\end{tabular}

Gambar 8 kategori delay (latency)[13]

Persamaan perhitungan delay (latency) :

$$
\text { Delay }=\frac{\text { Packet Length }}{\text { Linkbandwith }}
$$

Delay (latency) merupakan waktu yang diperlukan untuk melakukan perjalanan data dari pengirim ke penerima. Delay pada jaringan berbeda dengan kecepatan jaringan atau bandwidth yang merupakan jumlah data yang dapat dikirim per satuan waktu. Pada satu gambaran kecepatan jaringan $100 \mathrm{Mbps}$ berarti jaringan dapat mengirim 100 juta bit per detik, sedangkan delay atau latency pada jaringan 500 ms berarti data membutuhkan waktu 500 ms untuk mengirim data dari pengirim ke penerima[13].

\subsubsection{Throughput}

\begin{tabular}{|c|c|c|}
\hline $\begin{array}{c}\text { Kategori } \\
\text { Throughput }\end{array}$ & Throughput & Indeks \\
\hline Bad & $0-338 \mathrm{kbps}$ & 0 \\
\hline Poor & $338-700 \mathrm{kbps}$ & 1 \\
\hline Fair & $700-1200 \mathrm{kbps}$ & 2 \\
\hline Good & $1200 \mathrm{kbps}-2,1 \mathrm{Mbps}$ & 3 \\
\hline Excelent & $>2,1 \mathrm{Mbps}$ & 4 \\
\hline
\end{tabular}

Gambar 9 kategori throughput[13]

Persamaan perhitungan Throughput :

Throughput $=\frac{\text { Jumlah paket diterima }}{\text { Waktu }}$

Throughput mengukur berapa banyak paket yang tiba pada alamat tujuan dengan sukses. Pada umumnya kapasitas throughput diukur dalam skala bit per detik, tetapi juga dapat diukur dalam data per detik. Keberhasilan pengiriman paket merupakan kunci untuk layanan kualitas tinggi pada suatu jaringan. Paket yang hilang dalam proses pengiriman menyebabkan kinerja jaringan yang buruk dan throughput yang rendah menunjukkan masalah lain seperti hilangnya paket dalam proses pengiriman data[13]. Menggunakan throughput untuk mengukur kecepatan jaringan biasa dilakukan untuk deteksi masalah pada jaringan. 


\subsubsection{Packet Loss}

\begin{tabular}{|c|c|c|}
\hline $\begin{array}{c}\text { Kategori } \\
\text { Packet Loss }\end{array}$ & Packet Loss & Indeks \\
\hline Poor & $>25 \%$ & 1 \\
\hline Medium & $12-24 \%$ & 2 \\
\hline Good & $3-14 \%$ & 3 \\
\hline Perfect & $0-2 \%$ & 4 \\
\hline
\end{tabular}

Gambar 10 kategori packet loss[13]

Persamaan perhitungan packet loss :

Packet Loss $=\frac{(\text { Paket data kirim }- \text { paket data terima }) \times 100 \%}{\text { Paket data kirim }}$

Saat melakukan komunikasi antar perangkat pada suatu jaringan, bagian kecil dari data dikirim dan diterima dalam bentuk paket. Ketika satu atau lebih paket gagal mencapai tujuan, maka hal ini lah yang disebut packet loss. Ketika packet loss terjadi pada suatu jaringan hal tersebut mempengaruhi throughput karena satu atau lebih data tidak pernah diterima dan tidak dapat dihitung sebagai throughput. Ketika penurunan throughput terjadi karena packet loss, beberapa protokol layer transport mendefinisikan kehilangan paket sebagai indikasi kemacetan dan menyesuaikan laju transmisi jaringan[13].

\section{Hasil Penelitian dan Pembahasan}

\subsection{Hasil Pengujian Area Outdoor}

Tabel 2 Hasil perhitungan parameter QoS pada pengujian area indoor

\begin{tabular}{|c|c|c|c|c|c|c|c|c|}
\hline \multirow{2}{*}{$\begin{array}{c}\text { Jarak } \\
(\mathrm{m})\end{array}$} & \multirow{2}{*}{ Interferensi } & \multirow{2}{*}{$\mathrm{dbm}$} & \multicolumn{2}{|c|}{ Delay(s) } & \multicolumn{2}{|c|}{ Throughput(kbps) } & \multicolumn{2}{|c|}{ Packet loss(\%) } \\
\hline & & & Nilai & Indeks & Nilai & Kategori & Nilai & Kategori \\
\hline \multirow{3}{*}{1} & 0 Bluetooth & -33 & 0.0007445 & 4 & 10923,431208 & 2 & 0 & 4 \\
\hline & 2 Bluetooth & -34 & 0.000803583 & 4 & 9995,286688 & 2 & 0.003906 & 4 \\
\hline & 4 Bluetooth & -45 & 0.000796687 & 4 & 9991,01476 & 2 & 0.006398 & 4 \\
\hline \multirow{3}{*}{2} & 0 Bluetooth & -38 & 0.000771151 & 4 & 10449,714088 & 2 & 0.003764 & 4 \\
\hline & 2 Bluetooth & -43 & 0.000822059 & 4 & 9725,166696 & 2 & 0.00135 & 4 \\
\hline & 4 Bluetooth & -45 & 0.000860056 & 4 & 9391,7102 & 2 & 0.002806 & 4 \\
\hline \multirow{3}{*}{3} & 0 Bluetooth & -44 & 0.000742757 & 4 & 10799,21116 & 2 & 0.004869 & 4 \\
\hline & 2 Bluetooth & -46 & 0.00081658 & 4 & 9747,917368 & 2 & 0.013367 & 4 \\
\hline & 4 Bluetooth & -47 & 0.000900397 & 4 & 8897,372928 & 2 & 0.025581 & 4 \\
\hline \multirow{3}{*}{4} & 0 Bluetooth & -45 & 0.000782734 & 4 & 10311,026432 & 2 & 0.001270745 & 4 \\
\hline & 2 Bluetooth & -47 & 0.000807978 & 4 & 9896,417992 & 2 & 0.003937 & 4 \\
\hline & 4 Bluetooth & -50 & 0.000866122 & 4 & 9340,890752 & 2 & 0.001414 & 4 \\
\hline
\end{tabular}

Pada Tabel 2 menunjukkan nilai hasil penghitungan data pengujian pada area indoor dan mengkategorikan indeks kualitas parameter QoS Video streaming dengan skala kategori buruk, kurang, cukup, baik, dan sangat baik. Berdasarkan penghitungan yang telah dilakukan menunjukkan bahwa pengujian pada jarak 1,2,3 dan 4 meter dengan interferensi 0,2 dan 4 bluetooth di area indoor mendapatkan nilai delay dengan indeks 4 pada seluruh pengujian yang menunjukkan bahwa pengaruh interferensi bluetooth 5.0 terhedap delay yang dihasilkan ketika proses video streaming pada jaringan $802.11 \mathrm{~b}$ termasuk pada kategori sangat baik dengan nilai delay terendah pada jarak 1 meter dengan interferensi 0 bluetooth dan nilai delay tertinggi pada jarak 4 meter dengan interferensi 4 bluetooth. Nilai throughput mendapatkan indeks 2 pada seluruh pengujian indoor yang menunjukkan bahwa pengaruh interferensi bluetooth 5.0 terhadap throughput yang dihasilkan ketika proses video streaming pada jaringan $802.11 \mathrm{~b}$ termasuk pada kategori cukup dengan nilai throughput terendah pada jarak 3 meter dengan interferensi 4 bluetooth dan nilai throughput tertinggi pada jarak 1 meter dengan interferensi 0 bluetooth . Sedangkan nilai Packet loss mendapatkan indeks 4 pada seluruh pengujian indoor yang 
menunjukkan bahwa pengaruh interferensi bluetooth 5.0 terhadap packet loss yang dihasilkan ketika proses video streaming pada jaringan $802.11 \mathrm{~b}$ termasuk pada kategori sangat baik dengan nilai packet loss terendah pada jarak 1 meter dengan interferensi 0 bluetooth dan nilai packet loss tertinggi pada jarak 3 meter dengan interferensi 4 bluetooth.

\subsection{Hasil Pengujian Area Outdoor}

Tabel 3 Hasil perhitungan parameter QoS pada pengujian area outdoor

\begin{tabular}{|c|c|c|c|c|c|c|c|c|}
\hline \multirow{2}{*}{$\begin{array}{c}\text { Jarak } \\
(\mathrm{m})\end{array}$} & \multirow{2}{*}{ Interferensi } & \multirow{2}{*}{$\mathrm{dbm}$} & \multicolumn{2}{|c|}{ Delay(s) } & \multicolumn{2}{|c|}{ Throughput(kbps) } & \multicolumn{2}{|c|}{ Packet loss(\%) } \\
\hline & & & Nilai & Indeks & Nilai & Kategori & Nilai & Kategori \\
\hline \multirow{3}{*}{1} & 0 Bluetooth & -34 & 0.000782734 & 4 & 10311,026432 & 2 & 0.001270745 & 4 \\
\hline & 2 Bluetooth & -35 & 0.000807978 & 4 & 9896,417992 & 2 & 0.003937 & 4 \\
\hline & 4 Bluetooth & -40 & 0.000866122 & 4 & 9340,890752 & 2 & 0.001414 & 4 \\
\hline \multirow{3}{*}{2} & 0 Bluetooth & -39 & 0.000736429 & 4 & 10821,075808 & 2 & 0 & 4 \\
\hline & 2 Bluetooth & -40 & 0.000767903 & 4 & 10419,179384 & 2 & 0.003452 & 4 \\
\hline & 4 Bluetooth & -45 & 0.000790845 & 4 & 10097,748712 & 2 & 0.005151 & 4 \\
\hline \multirow{3}{*}{3} & 0 Bluetooth & -44 & 0.000715219 & 4 & 11162,4948 & 2 & 0.002329 & 4 \\
\hline & 2 Bluetooth & -46 & 0.000733751 & 4 & 10840,089952 & 2 & 0.004811 & 4 \\
\hline & 4 Bluetooth & -48 & 0.000761382 & 4 & 10499,111608 & 2 & 0.001234 & 4 \\
\hline \multirow{3}{*}{4} & 0 Bluetooth & -48 & 0.000822828 & 4 & 9718,045232 & 2 & 0 & 4 \\
\hline & 2 Bluetooth & -50 & 0.000877034 & 4 & 9161,302536 & 2 & 0.0029 & 4 \\
\hline & 4 Bluetooth & -54 & 0.000962146 & 4 & 8327,445984 & 2 & 0.003126 & 4 \\
\hline
\end{tabular}

Pada Tabel 3 menunjukkan nilai hasil penghitungan data pengujian pada area outdoor dan mengkategorikan indeks kualitas parameter QoS Video Streaming dengan skala kategori buruk, kurang, cukup, baik, dan sangat baik. Berdasarkan penghitungan yang telah dilakukan menunjukkan bahwa pengujian pada jarak 1,2,3 dan 4 meter dengan interferensi 0,2 dan 4 bluetooth di area outdoor mendapatkan nilai delay dengan indeks 4 pada seluruh pengujian yang menunjukkan bahwa pengaruh interferensi bluetooth 5.0 terhedap delay yang dihasilkan ketika proses video streaming pada jaringan $802.11 \mathrm{~b}$ termasuk pada kategori sangat baik dengan nilai delay terendah pada jarak 3 meter dengan interferensi 0 bluetooth dan nilai delay tertinggi pada jarak 4 meter dengan interferensi 4 bluetooth. Nilai throughput mendapatkan indeks 2 pada seluruh pengujian indoor yang menunjukkan bahwa pengaruh interferensi bluetooth 5.0 terhadap throughput yang dihasilkan ketika proses video streaming pada jaringan $802.11 \mathrm{~b}$ termasuk pada kategori cukup dengan nilai throughput terendah pada jarak 4 meter dengan interferensi 4 bluetooth dan nilai throughput tertinggi pada jarak 3 meter dengan interferensi 0 bluetooth . Sedangkan nilai Packet loss mendapatkan indeks 4 pada seluruh pengujian outdoor yang menunjukkan bahwa pengaruh interferensi bluetooth 5.0 terhadap packet loss yang dihasilkan ketika proses video streaming pada jaringan $802.11 \mathrm{~b}$ termasuk pada kategori sangat baik dengan nilai packet loss terendah pada jarak 2 dan 4 meter dengan interferensi 0 bluetooth dan nilai packet loss tertinggi pada jarak 4 meter dengan interferensi 4 bluetooth.

\section{Kesimpulan}

Pada penelitian ini telah dilakukan pengujian pengaruh interferensi bluetooth 5.0 terhadap kinerja jaringan $802.11 \mathrm{~b}$ dengan tolak ukur pengujian menggunakan parameter QoS Video Streaming pada jarak 1,2,3 dan 4 meter area indoor dan outdoor dengan skenario interferensi oleh 0 , 2, dan 4 perangkat bluetooth. Hasil pengujian menunjukkan bahwa nilai delay yang didapat ketika pengujian semakin tinggi ketika jumlah interferensi bluetooth semakin meningkat, nilai throughput yang didapat semakin rendah ketika jumlah interferensi bluetooth semakin meningkat, dan nilai packet loss semakin tinggi ketika jumlah interferensi bluetooth semakin meningkat. Dari hasil analisa terhadap data yang sudah didapat, bisa disimpulkan bahwa semakin banyak jumlah interferensi bluetooth 5.0 pada area jaringan $802.11 \mathrm{~b}$ maka performasi jaringan $802.11 \mathrm{~b}$ semakin menurun. 


\section{Refrensi}

[1] T. Xie, H. Hu, C. Yang, C. Zhang, and Z. Wang, "Design of IEEE 802.11b baseband receiver for indoor localization," EDSSC 2017 - 13th IEEE Int. Conf. Electron Devices Solid-State Circuits, vol. 2017-January, no. 4, pp. 1-2, 2017.

[2] A. Mathew, N. Chandrababu, K. Elleithy, S. Rizvi, and L. Almazaydeh, "Interference of 802.11B Wlan and Bluetooth: Analysis and Performance Evaluation," Int. J. Comput. Networks Commun., vol. 2, no. 3, pp. 140-150, 2010.

[3] S. Sendra, M. Garcia, C. Turro, and J. Lloret, "WLAN IEEE 802.11 a / b / g / n indoor coverage and interference performance study WLAN IEEE $802.11 \mathrm{a} / \mathrm{b} / \mathrm{g} / \mathrm{n}$ Indoor Coverage and Interference Performance Study," no. May 2014, 2011.

[4] A. Hasad, "Analisis Pengaruh Interferensi Wi-Fi Pada Video Streaming Melalui Jaringan Bluetooth Piconet Pervasive," Penelit. IImu Komput. Sist. Embed. dan Log., vol. 1, no. 1, pp. 55-64, 2013.

[5] I. Journal and C. Engineering, "Interference issues of WLAN $802.11 \mathrm{~b}$ with Other Devices in ISM 2 . 4 Ghz Band .," pp. 16-20, 2016.

[6] R. Purwaningsih, M. Malang, and G. Wasis, "Analisis Quality Of Service Terhadap Interferensi Bluetooth," vol. 1, no. 1, pp. 103-110, 2018.

[7] P. Titahningsih, R. Primananda, and S. R. Akbar, "Perancangan Penempatan Access Point untuk Jaringan Wifi Pada Kereta Api Penumpang," vol. 2, no. 5, pp. 2008-2015, 2018.

[8] E. W. Calvert, Kenneth L..Doar, Matthew B.Zegura, "Modeling internet topology," EEE Commun. Mag., 1997.

[9] M. N. Morshed, S. Khatun, L. M. Kamarudin, S. A. Aljunid, M. Fakir, and N. Azmi, "Performance measurement of $2.4 \mathrm{GHz}$ WLAN channels for overlapped and nonoverlapped Wi-Fi direct channel activity," Int. J. Microw. Opt. Technol., vol. 11, no. 4, pp. 268-273, 2016.

[10] E. Au, "Bluetooth 5.0 and Beyond," no. June, pp. 119-120, 2019.

[11] D. A. Diartono, "Teknologi Bluetooth untuk Layananan Internet pada Wireless Local Area Network," vol. XIV, no. 1, pp. 70-78, 2009.

[12] G. B. Horn, L. Jolla, and J. H. Yancey, "QUALITY OF SERVICE ( QOS ) MANAGEMENT IN WIRELESS NETWORKS," vol. 2, 2019.

[13] W. Sjb, "Evaluasi QOS Jaringan Komputer PT . PLN ( Persero ) Unit Induk," pp. 24-25, 2019. 